\title{
An assessment of the correlation between urban green space supply and socio-economic disparities of Tehran districts-Iran
}

\author{
Elmira Nasri Roodsari ${ }^{1}$ (D) Parian Hoseini ${ }^{2}$ (i)
}

Received: 2 November 2020 / Accepted: 10 November 2021 / Published online: 27 November 2021

(c) The Author(s) 2021

\begin{abstract}
Contact with UGS (urban green spaces) is a critical element for urban quality of life and an essential aspect of environmental justice, so all citizens should be able to access UGS regardless of their social and economic condition. In this regard, several studies have shown a positive correlation between UGS justice with socio-economic status in different contexts. In recent decades, Tehran has also experienced much wider socio-economic inequalities, reflected in its spatial configuration. Therefore, this study explored the possible correlation between the UGS supply and accessibility in the 22 Tehran municipal districts and their socio-economic development level. For this purpose, UGS supply (per capita) and accessibility (areas within $800 \mathrm{~m}$ walking distance to UGS) indicators are used to assess the UGS justice in Tehran. The research data are drawn from official spatial and statistical data, analysed using ArcGIS. This quantitative data are converted into map layers to shape a basis for UGS assessment indicators in conjunction with socio-economic status. The findings show an unbalanced distribution of UGS in Tehran. However, the areas with highest socio-economic status are at an optimum level of UGS justice in relation to all 22 districts, but no direct correlation confirms the same results for areas with lower socioeconomic status.
\end{abstract}

Keywords Urban green space - Urban green space distribution - Green space justice · Socio-economic Inequalities

Elmira Nasri Roodsari

st170344@stud.uni-stuttgart.de

Parian Hoseini

parian.hoseini@gmail.com

1 M.Sc. Integrated Urbanism and Sustainable Design, Faculty of Architecture and Urban Planning, University of Stuttgart, Stuttgart, Germany

2 Master of Urban Design, Department of Urban Planning and Design, Shahid Beheshti University, Tehran, Iran 


\section{Introduction}

As an essential part of urban ecosystem services, UGSs (urban green spaces) are increasingly acknowledged for their contribution to positive health behaviours, improved health outcomes (Ma et al., 2019; Müller et al., 2018; Remme et al., 2021; Sharifi et al., 2021; White et al., 2017), and promoting a reasonable nature-based solution to many urban challenges (Comber et al., 2008; Goodarzi et al., 2020; La Rosa, 2014; Soltanifard \& Jafari, 2019). However, in many cities, including Tehran, these UGSs, such as parks, public gardens, greenways, are heterogeneously distributed over the city. This means that the services they provide to improve residents' well-being that allow them to be exposed to nature are unfairly distributed throughout the city.

In this respect, many studies have stated a correlation between the UGS distribution and socio-economic status in different areas within a city (Astell-Burt et al., 2014; Schüle et al., 2017; Wen et al., 2013). These previous research has applied various UGS indicators to understand whether socio-economic inequalities or unbalanced development levels of a city's different areas can affect UGS justice (Boulton et al., 2018; Browning \& Lee, 2017; Jennings et al., 2012; Kabisch et al., 2017). They show that UGS justice assessments on a global scale need more comprehensive frameworks, which also comprise the effect of hidden and seemingly unrelated indicators such as the average income or the concentration of ethnic minorities in different areas of a city on equitable access to UGS. The results from the earlier studies also highlight the necessity to look beyond general standards, such as UGS per capita, that might mislead policymaking decisions (Boulton et al., 2018; Geneletti et al., 2020; Kabisch \& Haase, 2013; Mears et al., 2020).

Despite the fact that Tehran has become a socio-economically polarised city, where urban services and amenities have been distributed unfairly in its 22 municipal districts, most studies on UGS justice have continued to evaluate the quantitative indicators. Hence, the impact of the social and economic disparities on UGS supply and its distribution still remains a neglected topic in this context (Breuste \& Rahimi, 2015).

Therefore, this study set out to assess the correlation between the spatial distribution of UGS and the level of socio-economic development in 22 municipal districts of Tehran. The purpose of this research is to highlight whether the distribution of UGS in Tehran is just or has been affected by the prevailing socio-economic inequalities. Regarding, the specific questions which drive the research are:

- Does UGS per capita index in each district (which in this study includes green squares, urban parks, and other urban green spaces except the middle lane, roadside, and sidewalks) reflect a fair quantitative distribution of UGS in Tehran?

- How accessible are UGSs for these different municipal districts' residents based on a typically suitable walking distance that equals $800 \mathrm{~m}$ ?

- Is there a correlation between UGS distribution in terms of per capita, accessibility, and socio-economic inequalities in Tehran's urban districts?

According to an extensive literature review, two main UGS indicators are selected based on the study's scope and focus: UGS supply (per capita) and UGS accessibility (areas within $800 \mathrm{~m}$ or $10 \mathrm{~min}$ walking distance). The socio-economic development level of Tehran districts is adopted from the study conducted by Sadeghi and Zanjari (2017) that provides an overview of the socio-economic inequalities in 22 Tehran's municipal districts. 
GIS-based analysis of the city's districts and UGS shapefiles were used to calculate UGS supply and accessibility. Statistical analysis was then performed on the quantitative data extracted from the spatial analysis. To conclude, the final evaluations were carried out based on average and optimum UGS justice conditions within the districts to better understand the possible correlation between UGS distribution and socio-economic development level in Tehran, with a critical analysis of the applied indicators.

\subsection{Literature review}

As rapid urbanisation has changed human settlements into cities, far away from the natural environment, the need to contact nature has become a challenge for urban policymakers and planners. Access to UGS has been shown to contribute to human physical and mental well-being (Müller et al., 2018; White et al., 2017), providing ecosystem services such as climate regulation, capturing pollutants, or flood regulation (Geneletti et al., 2020), also promoting community integration, neighbours interactions, and delivering a favourable place for health, relaxation, and nature contemplation (Houlden et al., 2019; Ma et al., 2019). In general, UGS is considered public good that allows free access to all citizens and provides pockets of nature for all residents, including urban parks, squares, median strips, roadsides, sidewalks, etc. (De la Barrera et al., 2016). Given the importance of UGS, unequal access to them is considered an issue of environmental justice (Wolch et al., 2014), which in this case can be understood as the equal distribution of green infrastructure without discrimination within a city (de Sousa Silva et al., 2018).

There have been different approaches to evaluate green space justice in urban areas, mainly utilising GIS tools and examining quantitative, qualitative, and accessibility indicators (Boulton et al., 2018; De la Barrera et al., 2016; Kabisch \& Haase, 2014; La Rosa, 2014). In Tempa, Florida, USA, an equity study on the spatial distribution of street trees as an urban amenity was conducted by Landry and Chakraborty (2009). The suburbs' socioeconomic status is classified by race, ethnicity, income, and housing tenure, and the analysis of the urban amenity is undertaken by assessing the heterogeneity of urban land use, quantification of parcel-specific tree cover, and regression models. The outcome shows a lower proportion of tree cover in neighbourhoods where African-Americans, lower-income residents, and lower owner-occupation housing are dominant. Research on UGS distribution patterns and socio-economic status in Mumbai, India, integrates remote sensing-based UGS analysis with urban areas' socio-economic profiles. The results show that areas with higher socio-economic status have greater access to UGS than the areas with lower socioeconomic status, while there was no significant difference in the quantity of UGS in areas with a different range of socio-economic status (Sathyakumar et al., 2019). Another comprehensive study in the Metropolitan area of San Diego, Chile, examines UGS in three contrasting urban municipalities with the same political and economic system. The results show that due to the semi-arid climate, the maintenance costs of UGS are high, and the municipalities with lower income have difficulties in providing sufficient UGS in impoverished areas. At the same time, the high building density in these areas leaves a small proportion of land for planting (De la Barrera et al., 2016).

In a national study in the USA, Powell et al. (2004) used outdoor observational data on community-level, physical activity-related settings, coupled with census data, to examine green space provision concerning race and household income. Findings suggest that areas with higher poverty rates were significantly associated with reduced availability of green spaces, parks, and public sports areas, while in areas with a higher household income, a 
greater frequency of such amenities is witnessed. As Higgs (2012) suggests, ethnic minority neighbourhoods, such as those with predominantly African-American populations, were also associated with fewer green spaces, parks, and sports areas.

These studies represent various utilisation of indicators, definitions of UGS, and different methodologies. However, influenced by different factors, studies have shown a positive correlation between citizens' socio-economic status and UGS justice in both developed and developing countries. A common point inferred from these studies is that the quantitative indicators, especially the amount of UGS per inhabitant, do not provide comprehensive information for effective decision-making (De la Barrera et al., 2016). Therefore, additional indicators like accessibility have been widely used to examine access to green spaces in urban areas, often in the context with broader notions of environmental justice (Higgs et al., 2012).

In conclusion, to conduct a reliable assessment of UGS justice, certain indicators must be examined. These indicators can be classified into three types: UGS quantity, the quality, and accessibility to them; so, the main indicators for UGS justice that allow recognising inequalities in different urban contexts can be categorised in the same way (De la Barrera et al., 2016; Wood et al., 2017). Based on the research questions and the last updated and accessible official data of the case study, Tehran, the following indicators are identified as references for this study:

\subsubsection{The indicator associated with the quantity of UGS}

The most widely used quantitative indicator to assess green spaces is the ratio of the total area to the total population ( $\mathrm{m}^{2} /$ inhabitant) (Boulton et al., 2018; Browning \& Lee, 2017; De la Barrera et al., 2016; Kabisch \& Haase, 2013; Kabisch et al., 2017; Taylor et al., 2011). However, the quantitative indicator for evaluating UGS justice is not enough because it does not indicate the UGS's fair distribution, accessibility, or services (La Rosa, 2014; Yao et al., 2014). The UGS per capita index can be helpful for planners as a starting point or with limited data available, easily measured on GIS, that provides an overview of green infrastructure availability (Kabisch \& Haase, 2013).

\subsubsection{The indicator associated with the accessibility to UGS}

The other indicator to analyse UGS justice is assessing UGS accessibility based on walking distance, which relates to the spatial distribution of UGS throughout the urban area and is measured through a variety of GIS-based methodologies. This indicator can be combined with social surveys, which leads to a better understanding of the accessibility of residents and existing territorial inequalities (Higgs et al., 2012). It also can influence the frequent use of UGS among its users (De la Barrera et al., 2016). Hence, all the residential areas must have accessible and approachable UGS at various hierarchical levels to enhance urban quality of life (Higgs et al., 2012).

\subsection{Methodology}

The approach presented in this paper offers a generic method to evaluate the differences in the quantity and accessibility of UGS in conjunction with the socio-economic profiles of Tehran's municipal districts. Figure 1 shows an overview of research methods and data collection, followed by an explanation of why these methods were chosen. 


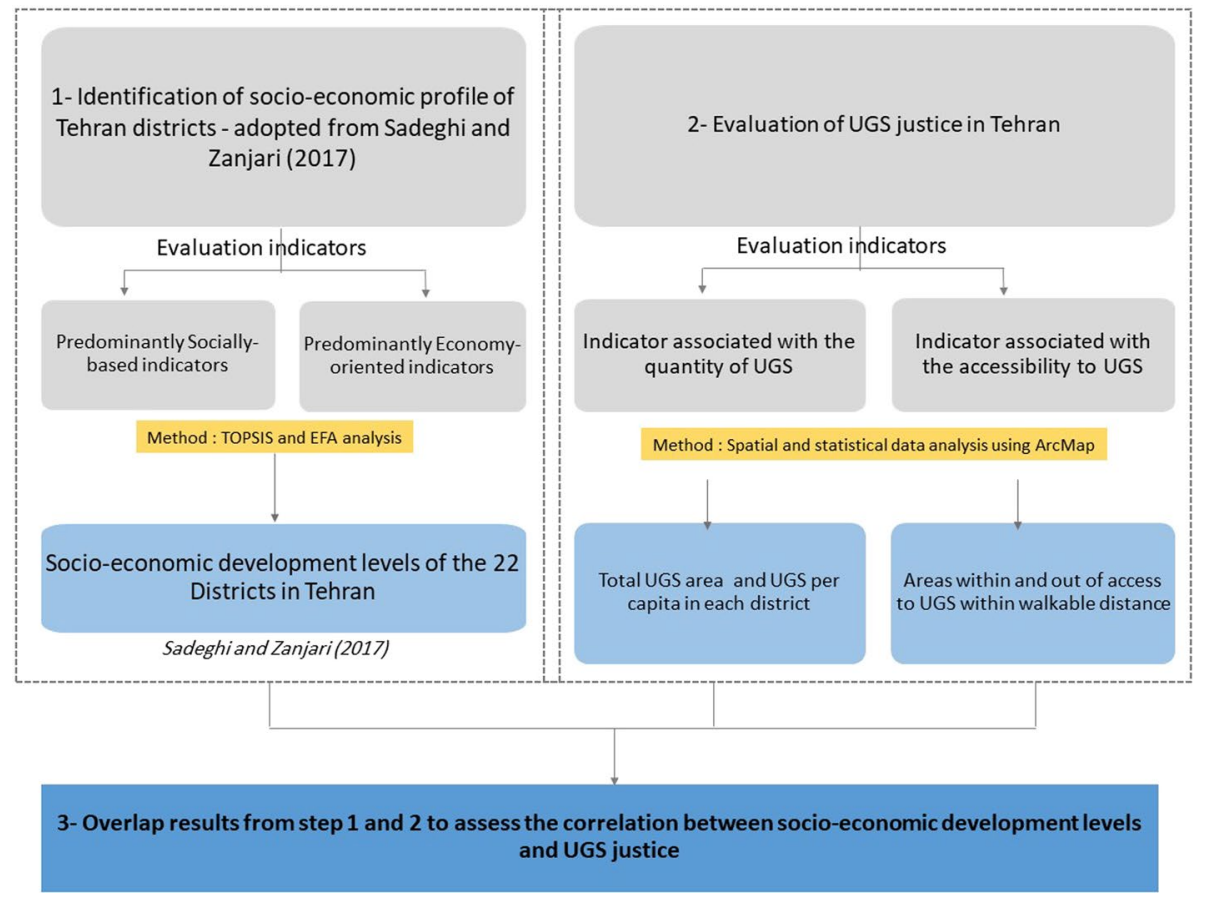

Fig. 1 Research methodology flowchart

The research procedure includes two major steps: I. identifying each urban districts' socio-economic development level. II. Evaluating UGS justice through calculating and analysing the spatial distribution of UGS in each urban district.

In the first step, the socio-economic profile of the city's districts is adopted from an existing study by Sadeghi and Zanjari (2017) since it represented the most relevant and updated information needed for the purpose of this research. The study investigates the extent and patterns of spatial inequality using the socio-economic index in 22 districts of Tehran. Indeed, a multi-criteria decision-making method is used to assess the socioeconomic development level of districts, based on 16 socio-economic-oriented indicators (Sadeghi \& Zanjari, 2017), as presented in Table 1.

Secondly, a spatial analysis using ArcMap is conducted on the city's shapefiles. The dataset, including all UGS areas, from linear sidewalk UGSs to forest parks and the city's districts was acquired from Tehran municipality. Indeed, the geographic data include the city's municipal districts and green spaces, produced by Iran National Cartographic Center in 2011. The map layers are made using spot satellite images and presented as 1:25,000 maps within the National Topographic Database. It is important to note that for improving the data accuracy, the geometric enhancement procedure was conducted in creating shapefiles (www.ncc.gov.ir). Then, to assess the quantity and distribution of UGS in each district, ArcMap tools are utilised to intersect the municipality district shapefile with the Tehran UGS shapefile. The UGS per capita is calculated in metres for each district, using the statistical population data (Municipality of Tehran, 2017). 
Table 1 Evaluated socio-economic indicators in Tehran districts. Source: (Sadeghi \& Zanjari, 2017)

\begin{tabular}{ll}
\hline Predominantly socially-based indicators & Predominantly economy-oriented indicators \\
\hline $\begin{array}{l}\text { The ratio of university graduates to the total popula- } \\
\text { tion }\end{array}$ & The ratio of employees with high-ranking jobs \\
$\begin{array}{l}\text { Percentage of women with university education } \\
\text { Percentage of men with university education }\end{array}$ & $\begin{array}{l}\text { Average monthly rent per residential square metre } \\
\text { Average selling price per square metre of residential } \\
\text { land }\end{array}$ \\
Internet usage rate & $\begin{array}{l}\text { Average property price per residential square metre } \\
\text { Elderly literacy level }\end{array}$ \\
The ratio of households with computers & $\begin{array}{l}\text { Adult literacy level } \\
\text { The ratio of households' access to public services }\end{array}$ \\
& Women's economic participation ratio \\
& House ownership ration \\
& Housing quality
\end{tabular}

Previous studies on UGS accessibility usually focus on two standard GIS methodologies (i) by buffering around UGS and integrating demographic characteristics within buffered areas, or (ii) by using network analysis to take into account actual routes with assumed walking speeds (Comber et al., 2008; De la Barrera et al., 2016; Gupta et al., 2016; Kabisch et al., 2017; La Rosa, 2014). Often the results of these analyses are integrated with nonspatial factors to investigate whether distributions are equitable (Higgs et al., 2012). As this research focuses on the metropolitan scale, covering all districts, the buffer zone method is used since including all pedestrian routes in such an analysis would require a broader study that is beyond the scope of this analysis. In this regard, to determine the appropriate distance in the buffer analysis method, the appropriate walking distance is the most commonly used metric, based on previous studies. (Carmen et al., 2020; El-Geneidy et al., 2010; Kabisch et al., 2017; Shuvo et al., 2020). The 10-min walking radius for reaching the basic amenities of the neighbourhood unit, such as green spaces, is a useful rule of thumb, and planners typically use it as the time people are willing to spend to walk to a destination (Langdon, 2017; Layton, 2014). Therefore, we used an 800-m distance, which corresponds to $10 \mathrm{~min}$ of walking at an average pace to access UGS within Tehran municipal districts. In this respect, a buffer zone surrounds $800 \mathrm{~m}$ around each UGS to indicate the UGS service area. The out of service areas are also identified by eliminating the service area buffer zones from the districts' total area. Finally, the quantitative data are extracted from this stage and statistically analysed to evaluate the correlation between the three indicators.

\subsection{Case study and evaluation}

Tehran is the home to around 8.7 million people of diverse ethnicities and social classes. It consists of 22 municipal districts and covers $730 \mathrm{~km}^{2}$ with a population density of 74 Inhabitants per hectare (StatisticalCenterofIran., 2016). This city is known for its omnipresent tension between "deep-seated tradition and wild modernity" (Madanipour, 2006). Tehran is socio-spatially divided into two completely opposite socio-economic poles, Bala Shahr and Paeen Shahr; so, groups of different income levels live separately. Bala Shahr (High City), located in the city's far north, includes the most affluent neighbourhoods. The middle to southern areas in Tehran, called Paeen Shahr (Low City), mainly include lowprice properties. These neighbourhoods are home to the poor, new rural migrants, and the 
lower strata of working people (Madanipour, 2006). Besides the physical and environmental advantages such as better water supplies, green spaces, and defensive and visual dominance over the city, Bala Shahr has also been associated with socio-cultural preferences (Bagheri, 2013). Thus, one of Tehran's critical features is its regional and spatial inequality, which in this study, the effect of these disparities on the fair distribution of green space is assessed.

\subsection{Identification of socio-economic profile of Tehran districts}

The extent and patterns of spatial inequalities based on the socio-economic index in the Tehran urban districts are extracted from an existing study by Sadeghi and Zanjari (2017). Results indicate that the highest degree of development belongs to district 3, and the lowest belongs to district 17. Using cluster analysis, the 22 districts of Tehran are classified into five categories in terms of socio-economic development levels, represented in Fig. 2. "Developed areas" ranked the highest in terms of socio-economic profile, and the "underdeveloped area" ranked the lowest.

\subsection{Evaluation of UGS justice indicators in Tehran}

In the second step, the spatial evaluation of UGS justice in Tehran is conducted. The assessment includes two indicators regarding the supply and the accessibility to UGS in Tehran. The urban green spaces are selected based on public use, including green squares, urban parks, and other UGS areas except for median strips, roadsides, and sidewalks. In this category, according to the official definitions in Iran, urban parks comprise neighbourhood

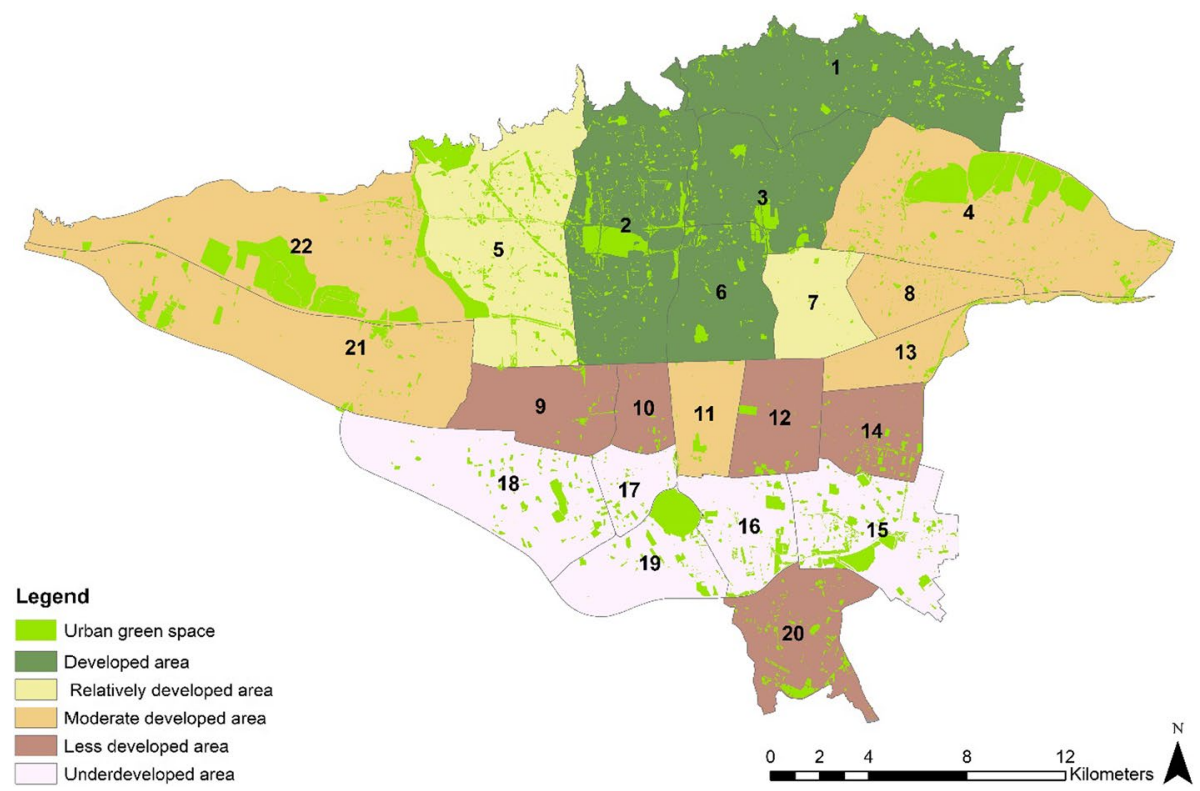

Fig. 2 Development levels of Tehran municipal districts. Source: Sadeghi and zanjari (2017) 
parks, local parks, parks on the scale of an urban area, and parks on a metropolitan scale (Taghizadeh \& Yahyavi, 2017).

\subsection{Indicators associated with the quantity of UGS}

The total UGS area is calculated separately for each urban district using the city's UGS and districts boundaries shapefiles. To indicate UGS per capita, the sum of UGS in each district is divided by the total population, as shown in Fig. 3 (Municipality of Tehran, 2017). As a result, the UGS per capita is calculated and illustrated in Fig. 4.

\subsection{Indicators associated with the accessibility of UGS}

In this step, the buffer tool in ArcMap was applied on Tehran's UGS shapefile to create buffer zones based on Table 2; the accessible UGS spots within $10 \mathrm{~min}$ of walking distance are identified and illustrated in Fig. 5.

Results from the GIS analysis show that there are significant out of green space service areas in western and southern Tehran, despite the existence of large-scale parks. As shown in Figs. 4 and 5, the distribution of small-scale green spaces in the city's eastern half leaves fewer areas out of $800 \mathrm{~m}$ of walking distance.

By eliminating areas within the buffer zone from the district's shapefile, areas outside the UGS service are identified. These areas are not accessible within 10 min walking distance. In Fig. 6, levels of development and out of UGS service areas are overlapped.

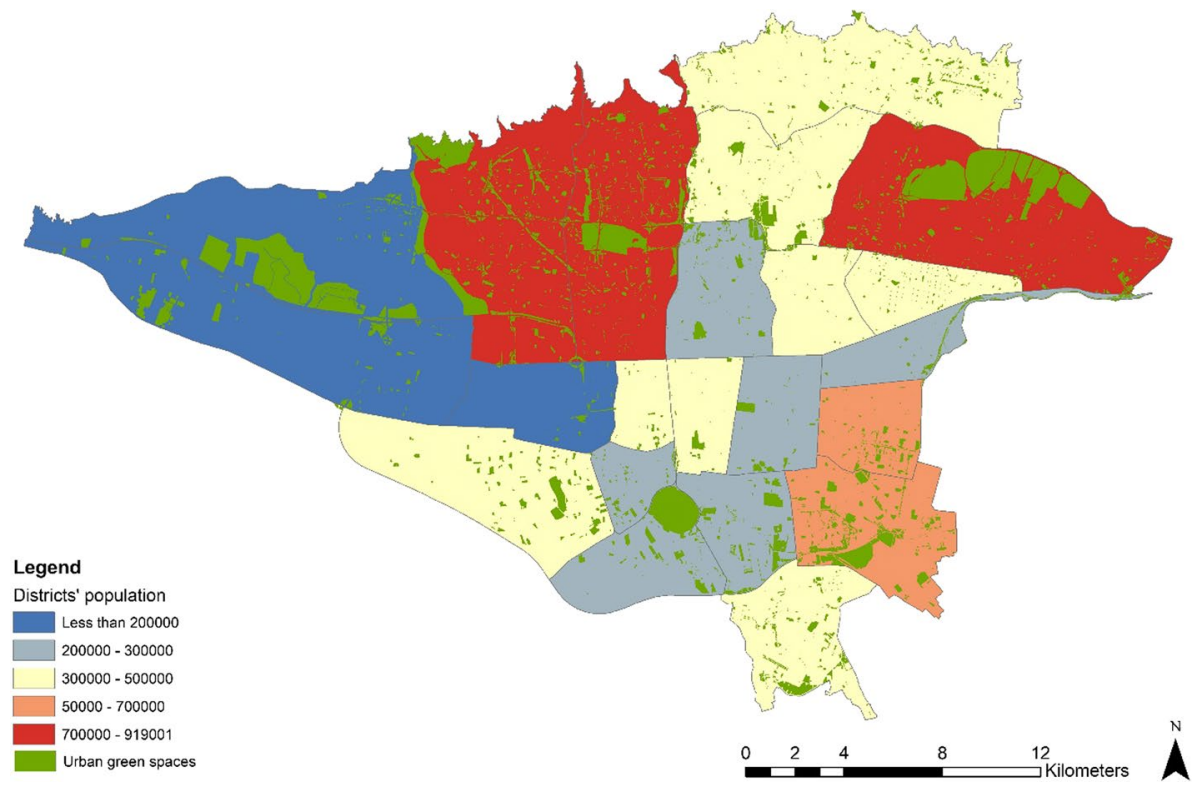

Fig. 3 Population of Tehran municipal districts. Source: (Municipality of Tehran, 2017) 


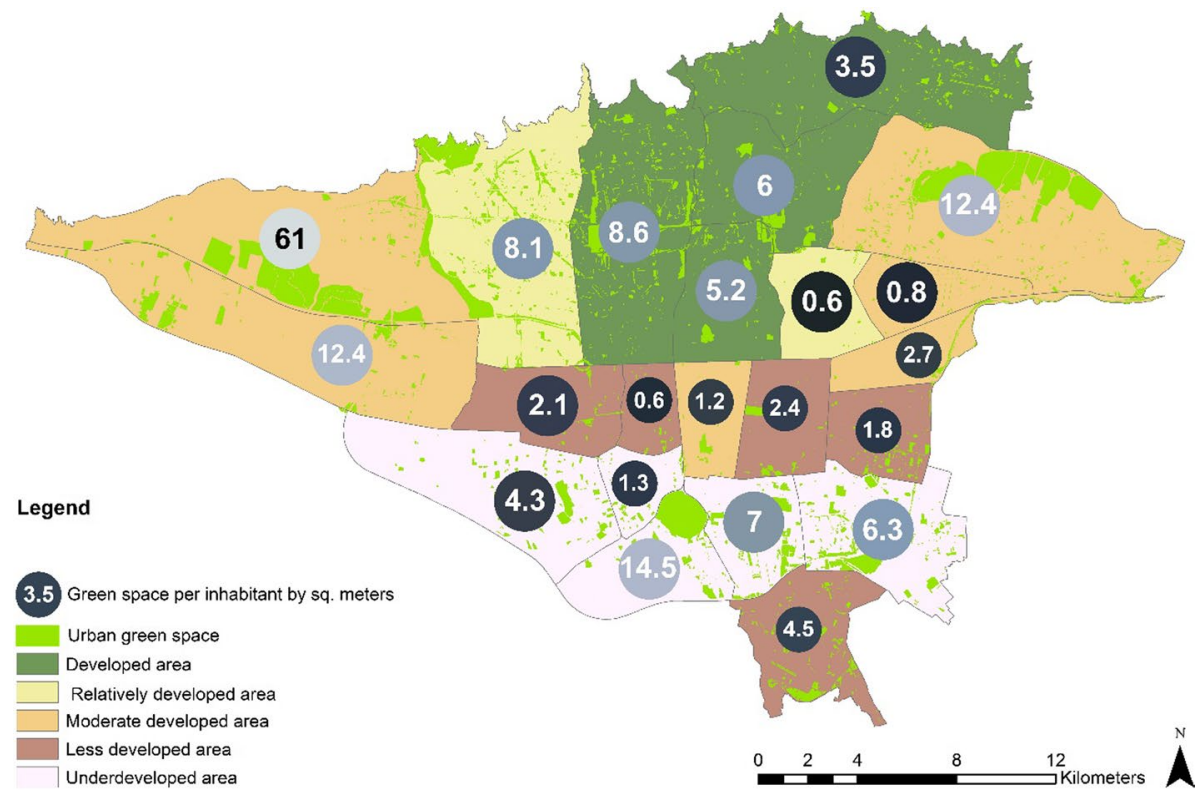

Fig. 4 Levels of development and GS per inhabitant in each district. Source: Authors

Table 2 Buffering criterion. Source: (El-Geneidy et al., 2010)

\begin{tabular}{lll}
\hline Walking accessibility & Time & $\begin{array}{l}\text { Walking dis- } \\
\text { tance/Buffer } \\
\text { diameter }\end{array}$ \\
\hline Good & Within $5 \mathrm{~min}$ & $400 \mathrm{~m}$ \\
appropriate & Within $10 \mathrm{~min}$ & $800 \mathrm{~m}$ \\
poor & Over $10 \mathrm{~min}$ & $\begin{array}{l}\text { All the areas } \\
\text { out of the } \\
\text { above buffer } \\
\text { zones }\end{array}$ \\
\hline
\end{tabular}

\section{Results and discussion}

This section evaluates the correlation between UGS justice indicators and socio-economic inequalities in 22 municipal districts of Tehran based on findings from the previous step. Table 3 represents the quantitative data derived from GIS analysis on UGS justice indicators, as well as their socio-economic development levels.

Due to the heterogeneity of quantitative data obtained from both UGS indicators, the median for UGS per capita (quantity) and areas outside UGS service coverage per cent (accessibility) is used for analysis. The reason for choosing the median as a reference is to compare different districts is because of the same geographical and political context, which are managed by a similar urban management model and observe their deviation from an average and an optimum condition. Indeed, by separating the data by the upper half from the lower half, this approach shows a relative division of these districts' conditions to the optimal and weak conditions, clarifying the deficiencies in both UGS 


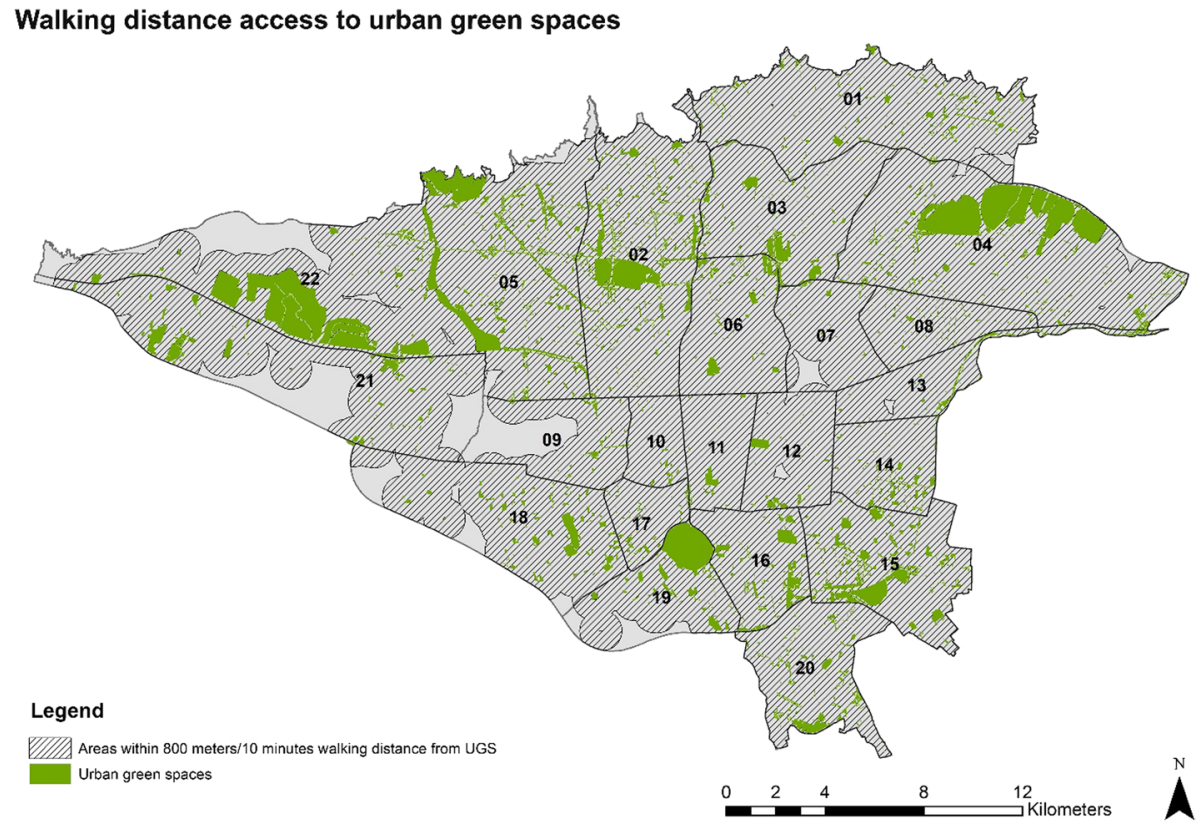

Fig. 5 Walking distance access to UGS. Source: Authors

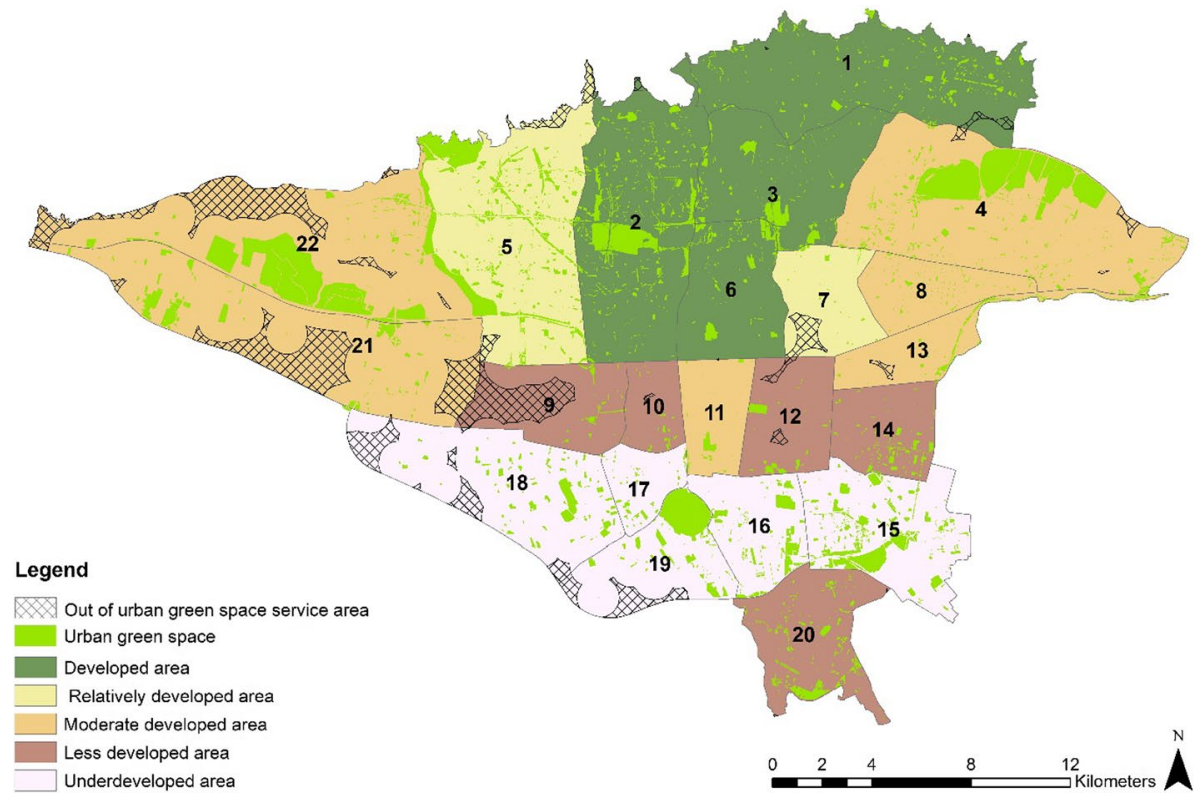

Fig. 6 Levels of development and out of UGS service areas in each district. Source: Authors 


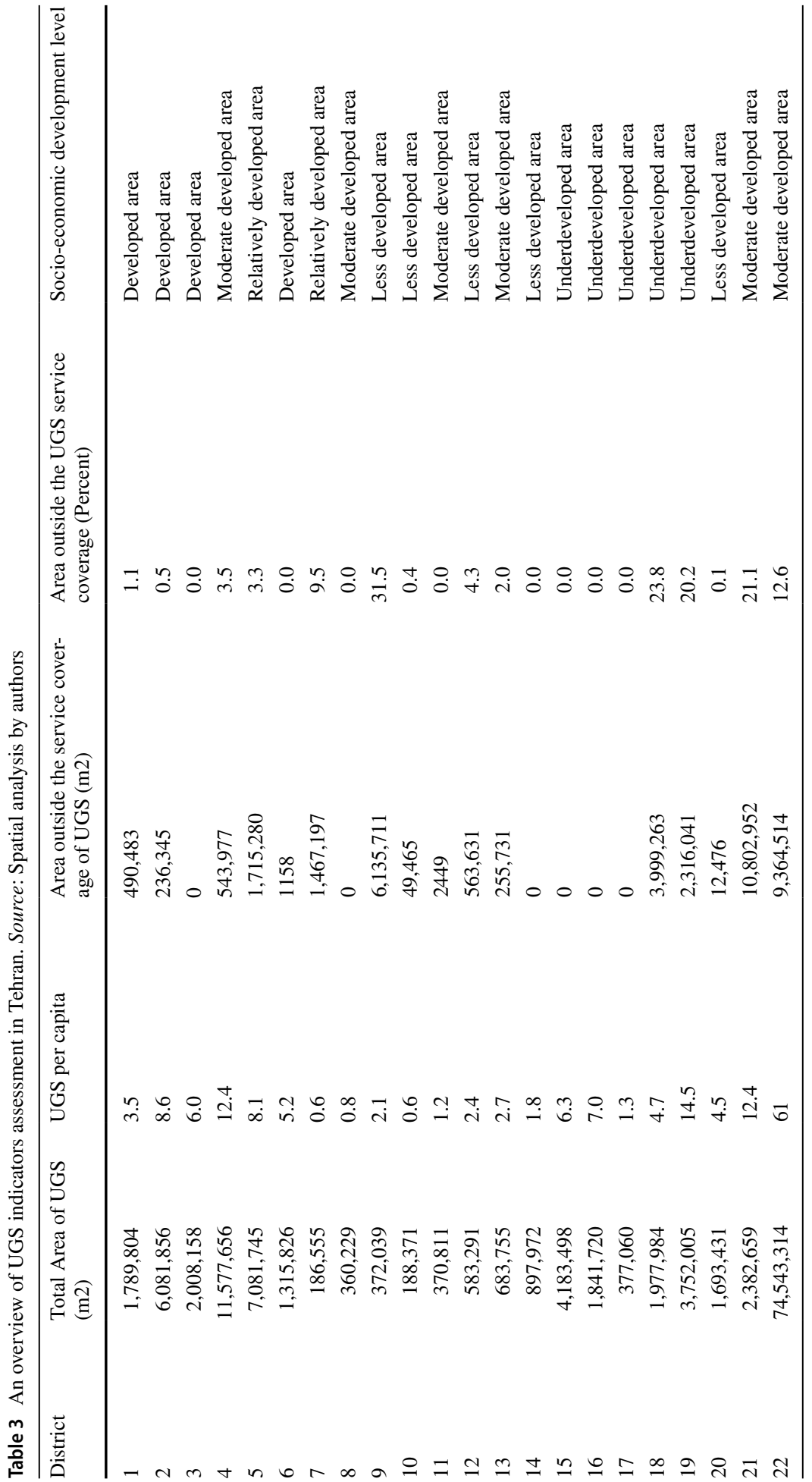


indicators individually. Using median rather than mean results in a much more accurate understanding of the inequality in the distribution of green spaces and access to them in different municipal districts since abnormalities will not skew the data.

The median of UGS per capita is $4.5 \mathrm{~m}^{2}$; therefore, districts $7,8,9,10,11,12,13$, 14, and 17 have a lower per capita than the median. Excluding district 7, all these areas are within the two lowest socio-economic development level categories. However, the number of underdeveloped districts, including 15, 16, 18, and 19, with higher than median per capita is also significant. On the other hand, except for district 7, all districts in the two highest socio-economic development level categories have equal to or higher than median UGS per capita. These findings show that districts with higher socio-economic status in Tehran benefit more from UGS provision, which is consistent with findings in some cases (De la Barrera et al., 2016; Landry \& Chakraborty, 2009; Powell et al., 2004), but does not indicate a direct relationship, as suggested by Landry and Chakraborty (2009) since underdeveloped districts in Tehran also have relatively high per capita.

The median for the area outside UGS service coverage is $0.5 \%$, and almost half of the districts have higher than the median value, meaning lower accessibility to UGS. Moreover, four districts are in critical condition: 19,21, 18, and 9, that over ten per cent of their total area lacks accessibility to UGS. On the other hand, the "developed district" has significantly better access to UGS. For instance, districts 3 and 6 have lower than the median, district 2 equals the median, and district 1 is slightly higher than the median ratio, which means good access to UGS. However, no correlation can be found in other categories. Therefore, the higher socio-economic status does not directly relate to better accessibility to UGS in Tehran, but the four areas with the highest socio-economic development level have better access to UGS. These findings are consistent with Sathyakumar et al. (2019) findings in Mumbai that shows better UGS accessibility in areas with higher socio-economic status.

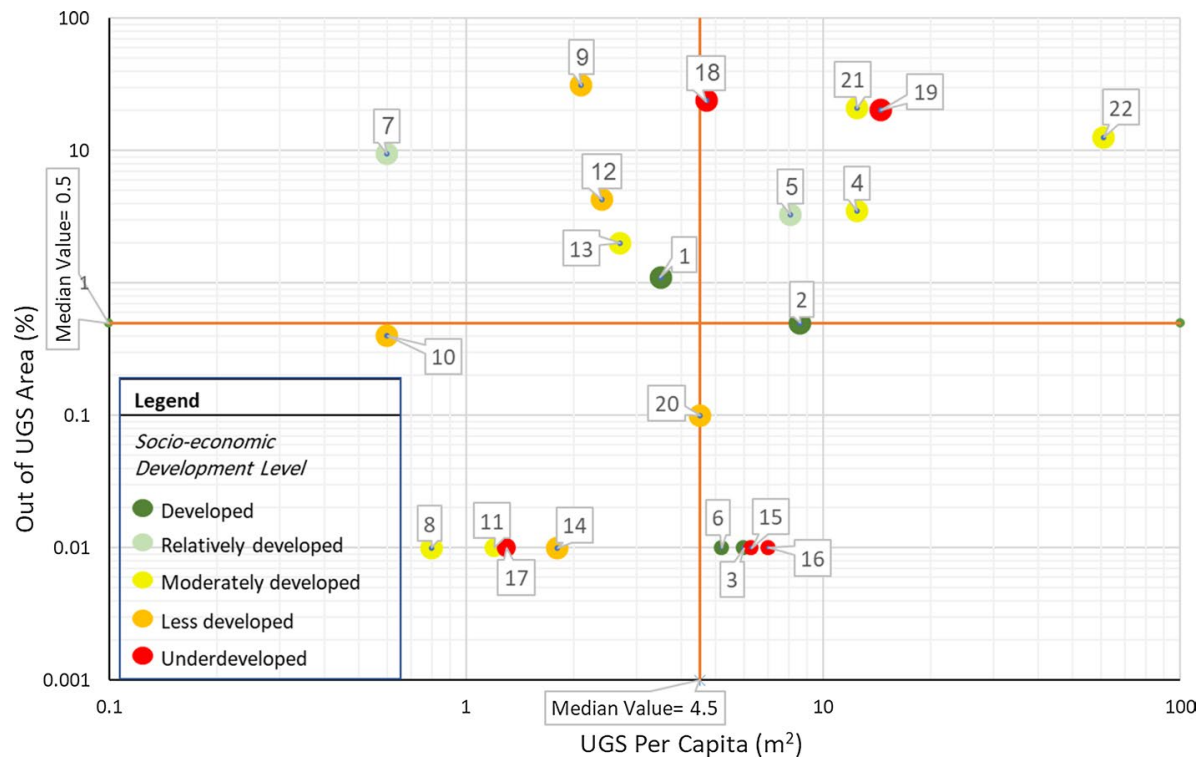

Fig. 7 UGS accessibility and provision for Tehran districts logarithmic scale 
As represented in Fig. 7, five districts have the optimum UGS provision and accessibility conditions: $2,3,6,15,16$, and 20 . They have a higher per capita area and lower out of UGS service coverage ratio. Districts 2, 3, and 6 belong to the "developed," districts 15 and 16 belong to the "underdeveloped," and district 20 is a "moderately" developed area. Therefore, the UGS justice indicators combination shows no direct relationship with the urban districts' socio-economic status in Tehran. This means that while some districts have above-median UGS per capita, the distribution of green space is not fair, and the percentage of area out of the UGS services is high.

\section{Conclusion}

This research studies the UGS justice and its correlation with the socio-economic status of the 22 municipal districts in Tehran. For this purpose, the socio-economic level of municipal districts was adopted from an existing study (Sadeghi \& Zanjari, 2017), and two main indicators for UGS, including the quantity of and the accessibility to UGS, were applied to assess the UGS justice in the 22 districts. The UGS supply is evaluated by the UGS per capita index in each district, and accessibility is assessed based on $10 \mathrm{~min}$ walking distance, equal to $800 \mathrm{~m}$. Spatial analysis was conducted within Tehran municipal districts and UGS map layers, and statistical analysis was conducted on the quantitative data extracted from the spatial analysis.

The results show that the UGS provision in Tehran is unbalanced and varies significantly among districts, as the wide range of per capita area suggests. Furthermore, the poor accessibility to the existing UGS areas also negatively influenced UGS justice, especially in the southern districts.

As the only significant correlation found in this study, in the four areas with the highest socio-economic development level, both indicators, the UGS accessibility and supply, are shown to be almost at an optimum level. Therefore, it can be concluded that the most affluent districts benefit the most from UGS advantages in Tehran; however, the opposite correlation is not valid. As also noted by Breuste and Rahimi (2015), the sharp inequality in UGS justice in the areas with the highest socio-economic status and other areas is a common phenomenon in Iranian cities, and the current research confirms the existing deficiencies in terms of UGS justice in Tehran.

Overall, these results indicate that UGS distribution in the whole city is unbalanced without any essential link between the UGS supply and the socio-economic status of Tehran's districts. As a noteworthy result of this research, it is shown that the high UGS per capita is not a reliable indicator for UGS justice evaluation because it does not capture details about the actual distribution of UGS across the city or different urban administrative units, as poor access to UGS would be a barrier for citizens to benefit from them. Therefore, a large-scale green space in an area that increases per capita might mislead decision-makers about the UGS policy. Indeed, a metropolitan area like Tehran needs to have large-scale UGS areas, but it is also necessary to provide all citizens with easily accessible small-scale UGS spots within their living environment. Furthermore, the results suggest that the distribution of smaller scale UGS spots within a metropolitan area can significantly improve UGS justice by increasing per capita number and accessibility. 


\section{Suggestions for future studies}

In addition to evaluated indicators in this paper, it is recommended to include a set of qualitative indicators like vegetation types, morphology, and services provided by green spaces in urban districts to better understand green space justice. Furthermore, the method used in this research can be helpful as a primary framework for measuring UGS justice indicators and other socio-economic criteria for future studies that help planners prioritise green space development and identify the requirements to enhance UGS justice. Also, applying the same method on a smaller scale, with more accurate data, indicators and analysis methods, especially for the accessibility status, can help achieve a better spatial analysis by considering existing access networks.

Funding Open Access funding enabled and organized by Projekt DEAL.

Open Access This article is licensed under a Creative Commons Attribution 4.0 International License, which permits use, sharing, adaptation, distribution and reproduction in any medium or format, as long as you give appropriate credit to the original author(s) and the source, provide a link to the Creative Commons licence, and indicate if changes were made. The images or other third party material in this article are included in the article's Creative Commons licence, unless indicated otherwise in a credit line to the material. If material is not included in the article's Creative Commons licence and your intended use is not permitted by statutory regulation or exceeds the permitted use, you will need to obtain permission directly from the copyright holder. To view a copy of this licence, visit http://creativecommons.org/licenses/by/4.0/.

\section{References}

Astell-Burt, T., Feng, X., Mavoa, S., Badland, H. M., \& Giles-Corti, B. (2014). Do low-income neighbourhoods have the least green space? A cross-sectional study of Australia's most populous cities. BMC Public Health, 14(1), 19-21. https://doi.org/10.1186/1471-2458-14-292

Bagheri, N. (2013). Modernising the public space: gender identities, multiple maternities, and space politics in Tehran. In Kansas City: University of Missouri (pp. 212-219). Springer.

Boulton, C., Dedekorkut-Howes, A., \& Byrne, J. (2018). Factors shaping urban greenspace provision: a systematic review of the literature. Landscape and Urban Planning, 178(May), 82-101. https://doi. org/10.1016/j.landurbplan.2018.05.029

Breuste, J., \& Rahimi, A. (2015). Many public urban parks, but who profits from them? The example of Tabriz Iran. Ecological Processes, 4(1), 1-15.

Browning, M., \& Lee, K. (2017). Within what distance does "greenness" best predict physical health? A systematic review of articles with gis buffer analyses across the lifespan. International Journal of Environmental Research and Public Health, 14(7), 1-21. https://doi.org/10.3390/ijerph14070675

Carmen, R., Jacobs, S., Leone, M., Palliwoda, J., Pinto, L., Misiune, I., Priess, J. A., Pereira, P., Wanner, S., Ferreira, C. S., \& Ferreira, A. (2020). Keep it real: Selecting realistic sets of urban green space indicators. Environmental Research Letters, 15(9). doi: https://doi.org/10.1088/1748-9326/ab9465

Comber, A., Brunsdon, C., \& Green, E. (2008). Using a GIS-based network analysis to determine urban greenspace accessibility for different ethnic and religious groups. Landscape and Urban Planning, 86(1), 103-114.

De la Barrera, F., Reyes-Paecke, S., \& Banzhaf, E. (2016). Indicators for green spaces in contrasting urban settings. Ecological Indicators, 62, 212-219.

de Sousa Silva, C., Viegas, I., Panagopoulos, T, \& Bell, S. (2018). Environmental justice in accessibility to green infrastructure in two European cities. Land, 7(4), 134.

El-Geneidy, A. M., Tétreault, P., \& Surprenant-Legault, J. (2010). Pedestrian access to transit: Identifying redundancies and gaps using a variable service area analysis. 89th Transportation Research Board Annual Meeting, July, 1-19. http://tram.mcgill.ca/Research/Publications/Transit_service_ area.pdf 
Geneletti, D., Cortinovis, C., Zardo, L., \& Esmail, B. A. (2020). Towards equity in the distribution of ecosystem services in cities. In Planning for Ecosystem Services in Cities (pp. 57-66). Springer.

Goodarzi, M., Haghtalab, N., Saeedi, I., \& Moore, N. J. (2020). Structural and functional improvement of urban fringe areas: toward achieving sustainable built-natural environment interactions. Environment, Development and Sustainability, 22(7), 6727-6754. https://doi.org/10.1007/s10668-019-00511-4

Gupta, K., Roy, A., Luthra, K., \& Maithani, S. (2016). GIS based analysis for assessing the accessibility at hierarchical levels of urban green spaces. Urban Forestry \& Urban Greening, 18, 198-211.

Higgs, G., Fry, R., \& Langford, M. (2012). Investigating the implications of using alternative GIS-based techniques to measure accessibility to green space. Environment and Planning $b$ : Planning and Design, 39(2), 326-343.

Houlden, V., Porto de Albuquerque, J., Weich, S., \& Jarvis, S. (2019). A spatial analysis of proximate greenspace and mental wellbeing in London. Applied Geography, 109(June), 102036. https://doi.org/ 10.1016/j.apgeog.2019.102036

Jennings, V., Johnson Gaither, C., \& Gragg, R. S. (2012). Promoting environmental justice through urban green space access: a synopsis. Environmental Justice, 5(1), 1-7. https://doi.org/10.1089/env. 2011.0007

Kabisch, N., \& Haase, D. (2013). Green spaces of European cities revisited for 1990-2006. Landscape and Urban Planning, 110, 113-122.

Kabisch, N., \& Haase, D. (2014). Green justice or just green? Provision of urban green spaces in Berlin, Germany. Landscape and Urban Planning, 122, 129-139.

Kabisch, N., van den Bosch, M., \& Lafortezza, R. (2017). The health benefits of nature-based solutions to urbanisation challenges for children and the elderly - a systematic review. Environmental Research, 159(July), 362-373. https://doi.org/10.1016/j.envres.2017.08.004

La Rosa, D. (2014). Accessibility to greenspaces: GIS based indicators for sustainable planning in a dense urban context. Ecological Indicators, 42, 122-134.

Landry, S. M., \& Chakraborty, J. (2009). Street trees and equity: evaluating the spatial distribution of an urban amenity. Environment and Planning A, 41(11), 2651-2670.

Langdon, P. (2017). Within walking distance: Creating livable communities for all. Island Press.

Layton, R. (2014). Tips For Locating Your Amenities. https://www.dcla.net/blog/walkability-standards

Ma, B., Zhou, T., Lei, S., Wen, Y., \& Htun, T. T. (2019). Effects of urban green spaces on residents' wellbeing. Environment, Development and Sustainability, 21(6), 2793-2809. https://doi.org/10. 1007/s10668-018-0161-8

Madanipour, A. (2006). Urban planning and development in Tehran. Cities, 23(6), 433-438.

Mears, M., Brindley, P., Jorgensen, A., \& Maheswaran, R. (2020). Population-level linkages between urban greenspace and health inequality: the case for using multiple indicators of neighbourhood greenspace. Health and Place, 62(July 2019). doi: https://doi.org/10.1016/j.healthplace.2020. 102284

Müller, G., Harhoff, R., Rahe, C., \& Berger, K. (2018). Inner-city green space and its association with body mass index and prevalent type 2 diabetes: a cross-sectional study in an urban German city. British Medical Journal Open, 8(1), 1-9. https://doi.org/10.1136/bmjopen-2017-019062

Municipality of Tehran. (2017). Tehran statistical yearbook.

Powell, L. M., Slater, S., \& Chaloupka, F. J. (2004). The relationship between community physical activity settings and race, ethnicity and socio-economic status. Evidence-Based Preventive Medicine, l(2), 135-144.

Remme, R. P., Frumkin, H., Guerry, A. D., King, A. C., Mandle, L., Sarabu, C., Bratman, G. N., GilesCorti, B., Hamel, P., Han, B., Hicks, J. L., James, P., Lawler, J. J., Lindahl, T., Liu, H., Lu, Y., Oosterbroek, B., Paudel, B., Sallis, J. F., \& Daily, G. C. (2021). An ecosystem service perspective on urban nature, physical activity, and health. Proceedings of the National Academy of Sciences of the United States of America, 118(22), 1-10. https://doi.org/10.1073/PNAS.2018472118

Sadeghi, R., \& Zanjari, N. (2017). The inequality of development in the 22 districts of Tehran metropolis. Social Welfare Quarterly, 17(66), 149-184.

Sathyakumar, V., Ramsankaran, R., \& Bardhan, R. (2019). Linking remotely sensed Urban Green Space (UGS) distribution patterns and Socio-Economic Status (SES)-A multi-scale probabilistic analysis based in Mumbai, India. Giscience \& Remote Sensing, 56(5), 645-669.

Schüle, S. A., Gabriel, K. M. A., \& Bolte, G. (2017). Relationship between neighbourhood socioeconomic position and neighbourhood public green space availability: an environmental inequality analysis in a large German city applying generalised linear models. International Journal of Hygiene and Environmental Health, 220(4), 711-718. https://doi.org/10.1016/j.ijheh.2017.02.006

Sharifi, F., Nygaard, A., \& Stone, W. M. (2021). Heterogeneity in the subjective wellbeing impact of access to urban green space. Sustainable Cities and Society. https://doi.org/10.1016/j.scs.2021.103244 
Shuvo, F. K., Feng, X., Akaraci, S., \& Astell-Burt, T. (2020). Urban green space and health in low and middle-income countries: A critical review. Urban Forestry and Urban Greening, 52(May 2021), 126662. https://doi.org/10.1016/j.ufug.2020.126662

Soltanifard, H., \& Jafari, E. (2019). A conceptual framework to assess ecological quality of urban green space: a case study in Mashhad city Iran. Environment, Development and Sustainability, 21(4), 1781-1808. https://doi.org/10.1007/s10668-018-0103-5

StatisticalCenterofIran. (2016). Population by country divisions in 2016. https://www.amar.org.ir

Taylor, B. T., Fernando, P., Bauman, A. E., Williamson, A., Craig, J. C., \& Redman, S. (2011). Measuring the quality of public open space using Google Earth. American Journal of Preventive Medicine, 40(2), 105-112.

Wen, M., Zhang, X., Harris, C. D., Holt, J. B., \& Croft, J. B. (2013). Spatial disparities in the distribution of parks and green spaces in the USA. Annals of Behavioral Medicine, 45(SUPPL. 1), 18-27. https://doi.org/10.1007/s12160-012-9426-X

White, M. P., Pahl, S., Wheeler, B. W., Depledge, M. H., \& Fleming, L. E. (2017). Natural environments and subjective wellbeing: Different types of exposure are associated with different aspects of wellbeing. Health and Place, 45(January), 77-84. https://doi.org/10.1016/j.healthplace.2017.03.008

Wolch, J. R., Byrne, J., \& Newell, J. P. (2014). Urban green space, public health, and environmental justice: the challenge of making cities' just green enough'. Landscape and Urban Planning, 125, 234-244.

Wood, L., Hooper, P., Foster, S., \& Bull, F. (2017). Health \& Place Public green spaces and positive mental health - investigating the relationship between access, quantity and types of parks and mental wellbeing. Health \& Place, 48(July), 63-71. https://doi.org/10.1016/j.healthplace.2017.09.002

Yao, L., Liu, J., Wang, R., Yin, K., \& Han, B. (2014). Effective green equivalent-a measure of public green spaces for cities. Ecological Indicators, 47, 123-127.

Publisher's Note Springer Nature remains neutral with regard to jurisdictional claims in published maps and institutional affiliations. 